\title{
Aortoduodenal Fistula: A Rare Case of Recurrence
}

\author{
Hasanin Al Chalabi ${ }^{\mathrm{a}, \mathrm{b}}$, Peter Lonergan ${ }^{\mathrm{a}}$, Sean Tierney ${ }^{\mathrm{a}}$, Martin Feeley ${ }^{\mathrm{a}}$
}

\begin{abstract}
Aortoduodenal fistula is seen as a sequence of erosion of the prosthetic graft into the small intestine, invariably causing a massive gastrointestinal hemorrhage. A prompt surgical intervention is essential to control the bleeding and to repair the intestinal defect. A recurrent case of such type of fistula is extremely rare.
\end{abstract}

Keywords: Aortoduodenal fistula; Aortoenteric fistula; Aortic bleeding

\section{Introduction}

Aortoduodenal fistula is a rare but potentially devastating cause of upper gastrointestinal tract hemorrhage; it is most commonly secondary to erosion of a prosthetic aortic graft material into the distal duodenum leading to a life threatening gastrointestinal tract hemorrhage. Without a surgical intervention, the outcome is universally fatal. Recurrences are extremely rare and it can present anywhere from 2 months to 6 years after the initial surgical repair with less than 10 cases reported in the literature worldwide [1-6]. We describe a unique case of a recurrent aortoduodenal fistula in a patient with a history of an infected aortic graft almost 2 years before presentation, who survived his initial fistula repair and developed a second fistula which is also repaired and was discharged home from the hospital after full recovery.

\section{Case Report}

A 54-year-old gentleman has a past surgical history of an aor-

\footnotetext{
Manuscript accepted for publication January 29, 2015

${ }^{a}$ Vascular Surgery Unit, Department of Surgery, AMNCH, Tallaght Hospital, Dublin 24, Ireland

${ }^{\mathrm{b} C}$ Corresponding Author: Hasan Al Chalabi, Department of Surgery, AMNCH, Tallaght Hospital, Dublin 24, Ireland. Email: hasan_chalabi@hotmail.com
}

doi: http://dx.doi.org/10.14740/jmc2045w tobifemoral bypass. However, he presented 8 months later to a university hospital in Brussels, Belgium with an aortoduodenal fistula secondary to an infected graft necessitating emergency surgery with excision of the infected material and graft re-doing using axillary bi-femoral bypass.

He then presented to the emergency department in our institution with a 3-day history of bleeding per rectum. On examination, the patient was hemodynamically stable and in no distress, and abdominal examination was unremarkable. Rectal examination was normal but stool was guaiac positive. Hemoglobin on admission was $11.4 \mathrm{~g} / \mathrm{dL}$. Esophagogastroscopy revealed an organized blood clot with a metallic foreign body in the distal duodenum (Fig. 1). A contrast enhanced computed tomogram (CT) was obtained, which revealed hyper-dense material in the distal duodenum communicating with the aorta, consistent with a fistula recurrence (Fig. 2). An emergency laparotomy was performed and a metallic coil was removed (Fig. 3), followed by a repair of the fistula. The patient had uneventful post-operative course, and was discharge home 2 weeks later.

\section{Discussion}

Aortoenteric fistula is a rare but a life threatening cause of up-

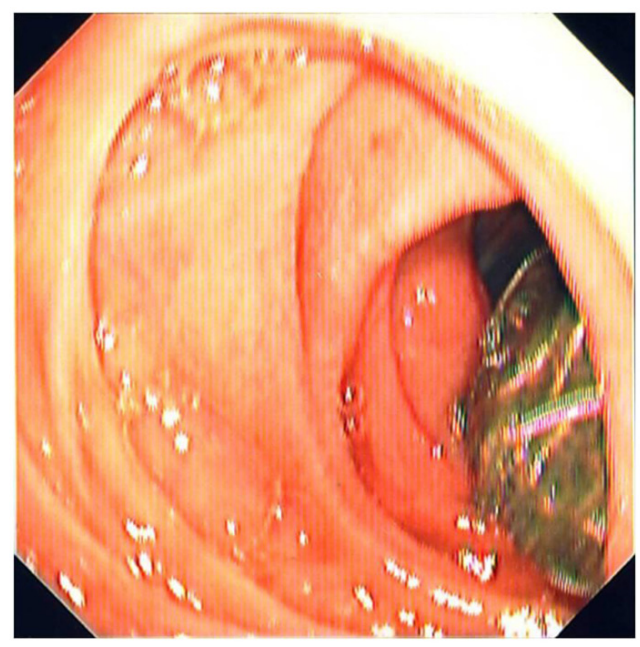

Figure 1. OGD picture showing the coil eroding into the duodenum. 


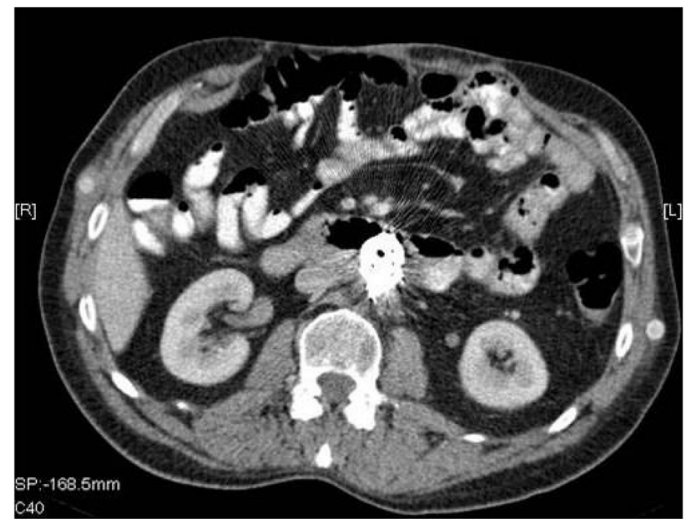

Figure 2. CT scan section showing the coil material eroding into the duodenum.

per gastrointestinal tract hemorrhage. The incidence is about $0.5-2.5 \%$ of all aortic grafts and can range from 2 weeks to 10 years post-operatively [7], and recurrent aortoduodenal fistula as in our case, is extremely unusual and rare. Aortoduodenal fistulae can be difficult to diagnose and high index of suspicion is often needed, and it should be considered for all patients with massive gastrointestinal tract hemorrhage and a history of thoracic or abdominal aortic aneurysm of prosthetic vascular graft repair. The classic clinical triad of gastrointestinal bleeding is a pulsatile abdominal mass and abdominal pains are observed with a frequency of $64 \%, 25 \%$ and $32 \%$ respectively [8]. A small self limiting "sentinel" bleed with a further massive re-bleeding and circulatory collapse occurring anywhere from few hours up to a week after the initial hemorrhage may occur [3]. The diagnostic sensitivity of endoscopy has been reported to be around 25\% [9]. However, its purpose is to exclude other causes of major gastrointestinal hemorrhage.

Conventional contrast enhanced CT scanning can demonstrate inflammatory changes around the vessel graft, such as peri-graft air locules or fluid changes, which is a diagnostic tool in around one-third of the cases [10]. Multiplanar contrast enhanced CT scan with three-dimensional reconstruction may prove an important non-invasive diagnostic tool in the future [11]. On the other hand, the diagnostic sensitivity of percutaneous aortography is reported to be less than 20\% [10]. However, angiograph with stenting to temporarily occlude an aortoenteric fistula [12] as well as endovascular balloon occlusion had been described [13]. These techniques may have a role in temporarily managing the hemorrhage before definitive surgery is performed. Ultimately if there is a high degree of clinical suspicion for an aortoenteric fistula, the best diagnostic and therapeutic modality remains with exploratory surgery when life threatening bleed is beyond the expertise of the interventional vascular radiologists. It is crucial to highlight that the literature reported that aortoenteric fistula is diagnosed in one-third of patients pre-operatively [14].

In conclusion, this most unusual case of second time development of aortoduodenal fistula despite previous surgical repair required a high index of a clinical suspicion with swift surgical intervention to save the life, when recurrence is a pos-

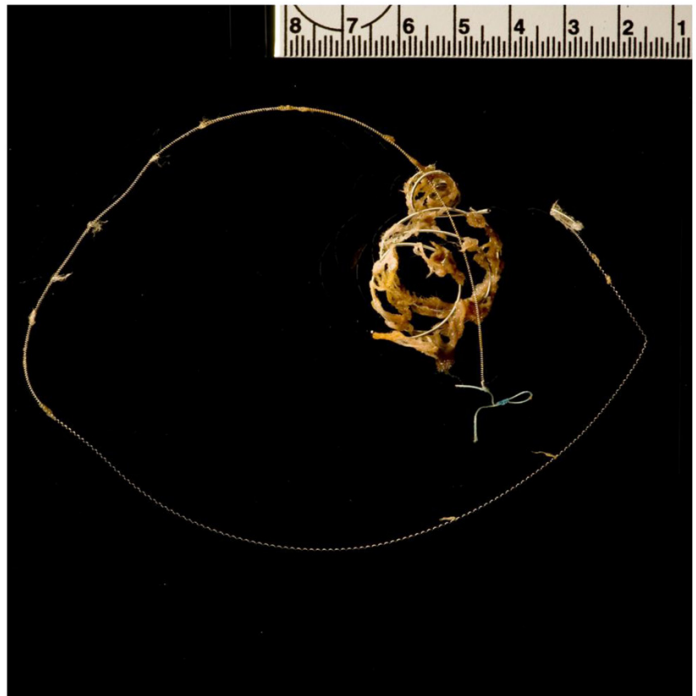

Figure 3. Coil material after being removed from the duodenal erosion.

sibility and low threshold for surgical intervention was the key in the success in the management of this case.

\section{Declaration}

No conflict of interest to be declared related to this manuscript.

\section{References}

1. Hill SL, Knott LH, Alexander RH. Recurrent aortoduodenal fistula: a lesson in management. Am Surg. 1982;48(3):137140.

2. Rao MM, Date R, Bateson P. Recurrent aortoenteric fistula. Ir Med J. 2003;96(4):112-113.

3. Goshtasby P, Henriksen D, Lynd C, Fielding LP. Recurrent aortoenteric fistula: case report and review. Curr Surg. 2005;62(6):638-643.

4. Makhdoomi KR, Gillies TE, Ruckley CV. Recurring aortoenteric fistula. Eur J Vasc Endovasc Surg. 1998;15(2):179181.

5. Scribner RG, Baker MS, Tawes RL, Brown WH, Harris EJ. Recurrent aortoduodenal fistula. Arch Surg. 1977;112(10):1265.

6. Wong RC, Pollack MJ. Recurrent aortoenteric fistula. Am J Gastroenterol. 2007;102(7):1547-1548.

7. Busuttil SJ, Goldstone J. Diagnosis and management of aortoenteric fistulas. Semin Vasc Surg. 2001;14(4):302-311.

8. Sweeney MS, Gadacz TR. Primary aortoduodenal fistula: manifestation, diagnosis, and treatment. Surgery. 1984;96(3):492-497.

9. Pipinos, II, Carr JA, Haithcock BE, Anagnostopoulos PV, Dossa CD, Reddy DJ. Secondary aortoenteric fistula. Ann Vasc Surg. 2000;14(6):688-696.

10. Daly CA, Nott DM, Padley SP. Aortoduodenal fistula: appearances on computed tomography. Aust N Z J Surg. 
1997;67(10):745-746.

11. Perks FJ, Gillespie I, Patel D. Multidetector computed tomography imaging of aortoenteric fistula. J Comput Assist Tomogr. 2004;28(3):343-347.

12. Hansen KS, Sheley RC. Aortoenteric fistula in advanced germ cell tumor: a rare lethal complication. J Urol.
2002;167(5):2131.

13. Loftus IM, Thompson MM, Fishwick G, Bell PR, London NJ. Technique for rapid control of bleeding from an aortoenteric fistula. Br J Surg. 1997;84(8):1114.

14. Peck JJ, Eidemiller LR. Aortoenteric fistulas. Arch Surg. 1992;127(10):1191-1193; discussion 1193-1194. 